\title{
Comparison of VIKOR and TOPSIS Methods in Multiresponse Taguchi Optimization
}

\author{
I Ketut Putu Suniantara $1^{1 *}$, I Gede Eka Wiantara Putra ${ }^{2}$
}

1,2 Program Studi Sistem Informasi, STIKOM Bali

A R T I C L E I N F O

Article history:

Received 19 May 2018

Received in revised

form

09 June 2018

Accepted 12 July 2018

Available online 28

August 2018

Keywords:

VIKOR, TOPSIS,

Multirespon Taguchi

\begin{abstract}
A B S T R A C T
Multirepon optimization in the Taguchi method can be done by using the VIKOR and TOPSIS approach, which are based on the concept that the best chosen alternative not only has the shortest distance from a positive ideal solution, but also has the longest distance from the negative ideal solution. The basic concept of these two methods is to determine the ranking of existing samples by looking at the results of the utility (S), regrets (R) and solution distances as the best alternatives for each sample. This study aims to obtain significant process variables on the brightness and soreness response variables in the envelope making process by using VIKOR and TOPSIS method approaches, and comparing the results of VIKOR and TOPSIS optimization. The results showed that the two methods produced process optimization in setting variables that were not the same. The VIKOR method produced a setting variable namely A3B2C1D1 while the TOPSIS method produced a setting variable A1B1C3D3. Looking at the value of the two methods, the VIKOR method produced a better estimated value of the brightness parameters and TOPSIS produced a better estimate value for the silence parameter.
\end{abstract}

Copyright (C) Universitas Pendidikan Ganesha. All rights reserved.

\section{Introduction}

The Taguchi method is a new method in the field of engineering to improve the quality of products and processes and can reduce costs and resources to a minimum. Initially the application and the Taguchi method theory were only for single response optimization or one response. But lately the Taguchi method has begun with multirespon, where in the case of multirespon there are several scientists who develop multirespon optimization methods, including Khuri and Conlon (1981) proposing a procedure that can optimize multiple variables simultaneously using a distance function to measure deviation from the ideal optimum value. Garg (2010) developed a method for multirespon cases using the Taguchi method and utility functions. Derringer and Suich (1980) developed the desirability function to show how some response variables can be transformed in that function. Refaie and $\mathrm{Li}$ (2008) developed a Data Envelopment Analysis (DEA) approach which examines multirespon Taguchi using the DEA method with aggressive formulations. Gaitode et al (2006) uses Taguchi quality loss function that examines multirespon optimization in the drilling process.

Lin et al (2000) with a fuzzy logics approach to optimize the process of removing and removing electrical engine materials to secure low and high ratio electrodes. Lu et al (2008) with the same approach at the Taguchi stage, parameter design to optimize the cutting process on the side of the mill. In addition to the above methods, Taguchi multirepon optimization can be done with other approaches, namely VIKOR and TOPSIS Multi Criteria Decision Making (MCDM). VIKOR and TOPSIS MCDM techniques are methods for multi-criteria optimization of complex systems that focus on ranking and selection of alternatives (Khezrian et al, 2011). The VIKOR and TOPSIS methods are useful in selecting problems in MCDM because the VIKOR and TOPSIS methods can work in situations where the tendency of users is difficult to clarify in the early stages of the selection process. 
The TOPSIS method is based on the concept that the best chosen alternative not only has the shortest distance from the ideal solution, but also has the longest distance from the negative ideal solution. The Taguchi method with signal-to-noise ratio ( $\mathrm{S} / \mathrm{N}$ ratio) to assess the performance of each response needs to be determined by its overall performance index (Overall Performance Index) for multirespon with a relative closeness to the ideal solution obtained from the TOPSIS method. The VIKOR method is a ranking method that considers the conditions between responses used for Multi Criteria Decision Making (MCDM). This method procedure can be used to determine the optimal solution between several conflicting alternatives. The optimization method will produce optimal levels of the tried-andtested factors, but the results are sometimes inconsistent so that the production is of less quality. This happens because the existing optimization procedure ignores diversity in quality loss for multirespon. This weakness can be overcome by the VIKOR method (Rahmasari, 2017).

Nike (2008) uses the Technique for Others approach by Similarity to Ideal Solution (TOPSIS) to overcome multi-phone optimization in paper making. Tong and Su (1997) introduced TOPSIS to deal with the multidimensional problem of the Taguchi method, where the TOPSIS procedure was developed through a fuzzy application set on Multiple Attribute Decision Making (MADM). The TOPSIS method is based on a concept where the chosen or best alternative not only has the closest distance from the positive ideal solution, but also has the farthest distance from the negative ideal solution. Suniantara (2013) used the VIKOR approach to overcome multirespon Taguchi in the process of making envelopes. Where in the study the VIKOR method was able to produce better estimated values. Mohammdiy and Amid (2010) presented thoroughly by combining fuzzy VIKOR and fuzzy AHP methods in decision making on service companies.

The stationery manufacturing industry is one of the manufacturing industries that has very tight competition. High quality and accuracy in meeting market demand are very important. One of the stationery products is an envelope. Where during this time the circulating envelopes were only used to send letters or documents under normal conditions. Charac-teristic critical to quality (CTQ) of an envelope that needs to be improved is the brightness of the inner and tackiness of the envelope. The specifications that must be met from brightness are $79-81 \mathrm{Lab}$, and the specifications for kesikuan (?L) are $0-1.25$ $\mathrm{mm}$.

This study aims to determine the optimal combination of process parameters in making envelopes and predict the response value in the optimal combination setting conditions with the VIKOR and TOPSIS methods and compare the results of both optimizations. These results are expected to provide information about the optimal combination of process parameters using the VIKOR and TOPSIS methods as an alternative in solving multirespon cases in the Taguchi method.

\section{Method}

The methodology used in this research is quantitative research where the research data is an experimental result, which is taken from the results of Setyabudhi's (2012) Technology Management Masters Program in the field of Industrial Management expertise. This study has two research variables, namely the response variable and the process variable which is the independent variable. The response variable consists of two variables, namely brightness and sophistication. While the independent variables consist of four factors, each of which has three levels. All variables can be seen in Table 1 below:

Table 1. Research Variable

\begin{tabular}{|c|c|c|}
\hline \multirow{2}{*}{ Response Variable } & \multicolumn{2}{|l|}{ Process Variable } \\
\hline & Factor & level \\
\hline $\begin{array}{l}\text { 1. Brightness } \\
\text { (Lab) }\end{array}$ & $\begin{array}{l}\text { 1. Engine rotational speed (factor A) } \\
\text { 2. Noodle speed (factor B) }\end{array}$ & $\begin{array}{l}A_{1}=85 \mathrm{rpm}, A_{2}=100 \mathrm{rpm}, A_{3}=125 \mathrm{rpm} \\
B_{1}=150 \mathrm{rpm}, B_{2}=225 \mathrm{rpm}, B_{3}=300 \mathrm{rpm}\end{array}$ \\
\hline $\begin{array}{l}\text { 2. Soreness } \\
(\mathrm{mm})\end{array}$ & $\begin{array}{l}\text { 3. Viscosity (factor C) } \\
\text { 4. Vacuum pump attraction (factor D) }\end{array}$ & $\begin{array}{l}\mathrm{C}_{1}=50 \mathrm{cp}, \mathrm{C}_{2}=75 \mathrm{cp}, \mathrm{C}_{3}=100 \mathrm{cp} \\
\mathrm{D}_{1}=35 \mathrm{psi}, \mathrm{D}_{2}=50 \mathrm{psi}, \mathrm{D}_{3}=75 \mathrm{psi}\end{array}$ \\
\hline
\end{tabular}

The data analysis technique used in this research is the ANOVA model in the Taguchi method with the determination of the number of sources of diversity based on orthogonal arrays (OA). The data analysis steps are as follows:

1. Determine the orthogonal array (OA) design. The selection of an orthogonal array $(\mathrm{OA})$ type that will be used in the experiment is based on the number of degrees of total freedom. In this study the orthogonal array (OA) design used in this study was L27 (313). Looking at orthogonal array (OA) L27 (313), the experiment was repeated 27 times with each response variable repeated three times. 
2. Calculate the $\mathrm{S} / \mathrm{N}$ ratio according to the characteristics of each response with the Taguchi method characteristics.

3. Analysis of the VIKOR Method, with the following steps: (a) Calculating the normalization value of the S / N ratio at each characteristic stage. (b) Determination of ideal and negative solutions is ideal. (c) Calculation of utility size (S) and regret (R) size. Calculation of weight values (w) uses a crips score which is transformed from fuzzy numbers. The weight values of each response are Brightness $=0.283$, then $w 1=$ $0.283 /(0.283+0.909)=0.2374$ and Adversity $=0.909$, then $w 2=(0.909 /(0.283+0.909))=0.7626$. (d) Calculation of the VIKOR index (Q). (e) Determine the optimal level of factors and combination levels. (f) Estimated value of optimum conditions in each response.

4. Analysis of the TOPSIS method, with the following steps: (a) Transform the relative importance of each response into a fuzzy number. (b) Marking the crisp score to choose the scale of conversion (fuzzy number) by transforming fuzzy numbers into scripsss scores using the fuzzy scoring method and normalizing the scrips score to obtain the weight value that represents each response. (c) Calculate loss functions based on the characteristics of each response. Calculation of the loss function of each response uses the characteristics in Taguchi. (d) Calculating the TOPSIS value for each combination of treatments by normalizing the value of the respective loss function and calculating the weighted normalization decision matrix. (e) Calculate negative ideal and ideal solutions as relative proximity distance. (f) Calculating the separator size of ideal and negative ideal solutions. (g) Calculating the TOPSIS value and determining the optimum combination level, the optimum combination of levels is obtained from a combination of factor levels that have the greatest TOPSIS value.

Comparison of estimated VIKOR results with Quality Loss Function and TOPSIS method.

\section{Findings and Discussion}

\section{Optimum Condition of Each Response}

This study has two response variables with different characteristics. The quality of brightness leads to a certain number of values that have been determined as the target quality to be better (nominalthe-best) as the first response. While the measurement for quality characteristics in the oversight response is the smaller the difference between the length of the envelope side, the smaller - the - better quality is the second response. Calculation of the $\mathrm{S} / \mathrm{N}$ ratio on the effect of each factor is used to see the important influence of the factors on the response. The results of this calculation can be seen in Table 2 .

Table 2. Calculation of S / N Ratio on the Effect of each Factor in each Response

\begin{tabular}{lllllllll}
\hline \multirow{2}{*}{ Level } & \multicolumn{7}{l}{ Brightness } & Soreness \\
\cline { 2 - 9 } & A & B & C & D & A & B & C & D \\
\hline 1 & 46,657 & 44,634 & 45,423 & 43,575 & 5,453 & 5,036 & 4,551 & 1,537 \\
2 & 46,190 & 47,161 & 46,701 & 42,723 & 4,666 & 2,647 & 3,667 & 3,682 \\
3 & 42,813 & 43,864 & 43,537 & 49,362 & 1,938 & 4,374 & 3,839 & 6,838 \\
Difference & 3,844 & 3,297 & 3,163 & 6,640 & 3,515 & 2,389 & 0,884 & 5,301 \\
\hline Rank & 2 & 3 & 4 & 1 & 2 & 3 & 4 & 1 \\
\hline
\end{tabular}

Based on Table 2, it can be seen that D factor (vacuum pump suction pressure) has a very important influence on the brightness and soreness response which ranks 1 with the largest difference value, followed by factor A (engine rotational speed) in rank 2, and then B (mixer rotational speed) and factor C (ink viscosity) respectively in rank 3 and ranking 4. Optimum conditions at the level of each factor used to optimize the response. The main factors that influence the response are the rotating speed of the engine, mixer rotational speed, viscosity and pressure factor of the vacuum pump. The optimum condition of each factor can be seen in Figure 1 that the optimum condition in the brightness response is A1B2C2D3 and Figure 2. The optimum condition in the response is seen A1B1C1D3. 


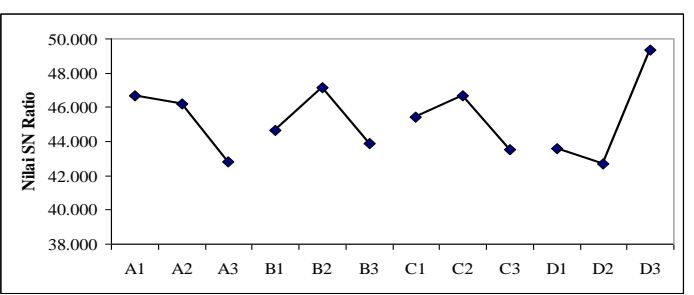

Picture 1. Effect Ratio S / N Brightness Response.

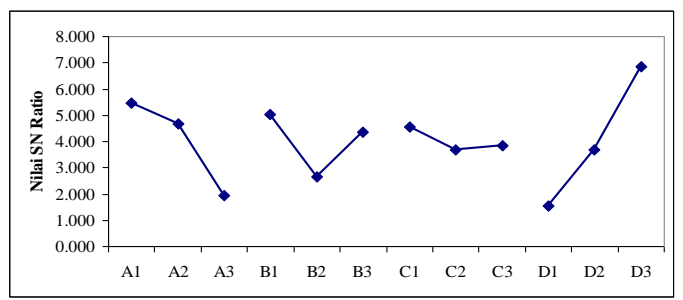

Picture 2. Effect ratio S/N Soreness Response.

Based on individual analysis, the level of factors that can optimize each response is obtained for the response of optimum conditions for Brightness A1B2C2D3 and the response to the optimum conditions A1B1C1D3. Because the two responses do not produce the same optimum conditions, so an additional method is needed to deal with the multirespon Taguchi problem. According to Satheesh and Dhas (2013) the Taguchi method can only be used to solve a single response optimization problem. When dealing with multirespon problems, partial resolution of each response becomes ineffective and results in a combination of optimal level parameters that are not consistent between responses because not all responses have the same characteristics. Thus a statistical calculation is needed to find the right combination in the case of a multirespon experimental design, one of them is the VIKOR and TOPSIS methods.

\section{Optimum Condition with VIKOR and TOPSIS Methods}

The first step procedure in VIKOR and TOPSIS calculations is done by calculating loss quality based on the characteristics of the Taguchi method. Furthermore, the results of this calculation are analyzed based on the VIKOR and TOPSIS methods. VIKOR and TOPSIS calculations produce index values for each method. The VIKOR method has the smallest index value that is the best, while the TOPSIS method is the largest index value as the best solution. The results of the calculation of this index are carried out to determine the optimal level of factors from the combination of levels. The results of the calculation of the effect of factor effects on the combination of levels against the VIKOR and TOPSIS values can be seen in Table 3.

Table 3. Score Calculation of VIKOR and TOPSIS in Each Factor Level

\begin{tabular}{lllllllll}
\hline \multirow{2}{*}{ Level } & \multicolumn{7}{l}{ VIKOR Method } & \multicolumn{7}{l}{ TOPSIS Method } \\
\cline { 2 - 9 } & A & B & C & D & A & B & C & D \\
\hline 1 & 0,1856 & 0,2543 & 0,3036 & 0,3946 & 0,80789 & 0,74130 & 0,69885 & 0,57413 \\
2 & 0,2112 & 0,3142 & 0,2561 & 0,3287 & 0,75468 & 0,66302 & 0,71643 & 0,66459 \\
3 & 0,4157 & 0,2441 & 0,2528 & 0,0893 & 0,57089 & 0,72914 & 0,71817 & 0,89474 \\
Difference & 0,2300 & 0,0701 & 0,0508 & 0,3053 & 0,23700 & 0,07828 & 0,01932 & 0,32061 \\
\hline Rank & 2 & 3 & 4 & 1 & 2 & 3 & 4 & 1 \\
\hline
\end{tabular}

Based on Table 3 above, it can be seen that factor D (attraction of vacuum pump) is the most influential in both responses. This can be seen from the biggest difference in value and ranked first. Then followed by factor A (engine rotational speed) in rank 2, then factor B (mixer rotational speed) and factor $\mathrm{C}$ (ink vikosity) with each ranked 3 and ranking 4. Optimum conditions at the level of each factor can be seen in Figure 3 is used to optimize the response of each method.

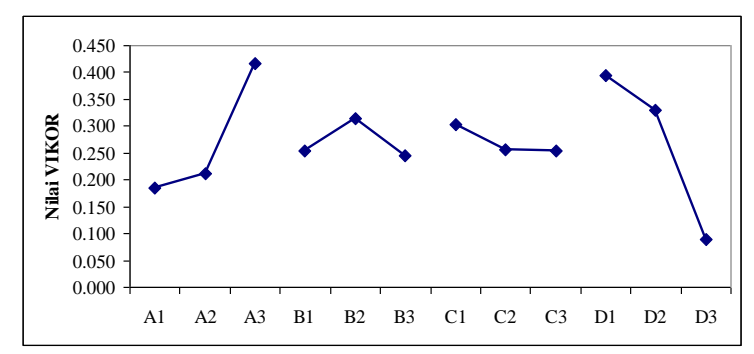

Picture 3 (a). Factor Effect of VIKOR Scores

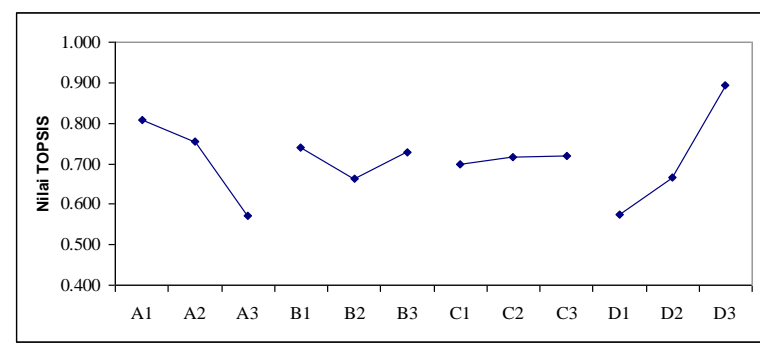

Picture 3 (b). Factor Effect of TOPSIS Scores 
In Figure 3 (a) it can be seen that the optimum conditions in both responses are A3B2C1D1 for the VIKOR method, namely: Factor A Engine rotational speed with a maximum speed of $150 \mathrm{rpm}$. Factor B Mixer speed of mixer with medium mixer speed $225 \mathrm{rpm}$. Factor C Viscosity with a minimum vikosity of $50 \mathrm{cP}$ and factor D The suction pressure of the vacuum pump valve is opened in half with suction pressure reaching 35 psi. Figure 3 (b) shows that the optimum conditions in both responses are A1B1C3D3, namely: Factor A Minimum engine speed of $85 \mathrm{rpm}$. Factor B medium mixer play speed $150 \mathrm{rpm}$. Factor $\mathrm{C}$ Minimum viscosity of $50 \mathrm{cP}$ and factor D The vacuum pump suction pressure valve is fully opened with suction pressure reaching 75 psi for the TOPSIS method.

\section{Percentage of Contributions to Each Factor}

Percentage of contribution is done to find out how much contribution given by each factor and interaction can be seen in Table 4 .

Table 4. Contribution Percentage

\begin{tabular}{llllll}
\hline SK & DF & SS & MS & SS' & Contribution percentage \\
\hline A & 2 & 0,286 & 0,143 & 0,256 & $21,564 \%$ \\
B & 2 & 0,026 & 0,012 & $-0,004$ & $0,348 \%$ \\
C & 2 & 0,014 & 0,007 & $-0,015$ & $1,300 \%$ \\
D & 2 & 0,465 & 0,232 & 0,435 & $36,593 \%$ \\
AxD & 4 & 0,127 & 0,032 & 0,068 & $5,689 \%$ \\
CxD & 4 & 0,119 & 0,029 & 0,059 & $5,007 \%$ \\
Error & 10 & 0,150 & 0,015 & & \\
Total & 26 & 1,188 & & & \\
\hline
\end{tabular}

Based on Table 4 the calculation of the percentage contribution from the main factor and the interaction shows that the attraction of vacuum pumps (factor D) contributes the most to the two responses compared to other factors, which is $36.593 \%$. Then followed by the engine rotational speed (factor A) which gives the second largest contribution of $21.564 \%$. While other factors and combination levels only contribute under $10 \%$ to the two responses.

\section{Comparison of Estimated VIKOR and TOPSIS Methods}

The estimated value for each response is obtained by using the optimum conditions for the average value that has been known to be the optimum combination of levels. The comparison of the optimum condition value obtained from the analysis using the VIKOR and TOPSIS methods aims to find out which value is better to give optimum results. Estimated optimum value can be seen in Table 5 .

Table 5. Comparison of Estimated Value and 90\% Confidence Interval in VIKOR and TOPSIS Optimization

\begin{tabular}{|c|c|c|c|c|c|}
\hline Method & $\begin{array}{l}\text { Optimum } \\
\text { Condition }\end{array}$ & Response & $\begin{array}{l}\text { Estimated } \\
\text { Value }\end{array}$ & $\mathrm{CI}$ & Charateristic \\
\hline \multirow{2}{*}{ VIKOR } & \multirow{2}{*}{$\mathrm{A}_{3} \mathrm{~B}_{2} \mathrm{C}_{1} \mathrm{D}_{1}$} & Brightness & $\begin{array}{l}43,312 \\
79,772\end{array}$ & $\begin{array}{l}43,039<\hat{\eta}<43,585 \\
79,449<\hat{\mu}<80,045\end{array}$ & Nominal the best \\
\hline & & Soreness & $\begin{array}{l}-1,364 \\
1,139\end{array}$ & $\begin{array}{l}-1,463<\hat{\eta}<-1,305 \\
1,060<\hat{\mu}<1,218\end{array}$ & Smaller the better \\
\hline \multirow{2}{*}{ TOPSIS } & \multirow{2}{*}{$\mathrm{A}_{1} \mathrm{~B}_{1} \mathrm{C}_{3} \mathrm{D}_{3}$} & Brightness & $\begin{array}{l}48,531 \\
81,031\end{array}$ & $\begin{array}{l}48,258<\hat{\eta}<48,804 \\
80,758<\hat{\mu}<81,304\end{array}$ & Nominal the best \\
\hline & & Soreness & $\begin{array}{l}9,109 \\
0,269\end{array}$ & $\begin{array}{l}9,030<\hat{\eta}<9,188 \\
0,190<\hat{\mu}<0,348\end{array}$ & Smaller the better \\
\hline
\end{tabular}

Based on Table 5 shows that the results of the optimization based on the average by the VIKOR method produce a better estimated value of the brightness parameters with the best nominal characteristics, namely 79.722 which approaches the target value of 80 Labs from the 79 - 81 Lab interval limit compared to the TOPSIS method. Whereas in the parameters of weariness the TOPSIS method 
produces a better estimated value than the VIKOR method by producing an estimated value of $0.269 \mathrm{~mm}$ with smaller the better characteristics in the specifications $0-1.25 \mathrm{~mm}$. In the confidence interval shows the value of the $90 \%$ confidence interval the average brightness at optimum conditions with the VIKOR method between 79,449 and 80,045 , and the TOPSIS method with a $90 \%$ confidence interval located between 80,758 and 81,304. Judging from the interval the estimated VIKOR method has a better confidence interval by approaching the 80 Lab target.

The average estimated value in the response time with a $90 \%$ confidence interval on the VIKOR method between 1.060 to 1,218 , and the TOPSIS method the average estimated value with a $90 \%$ confidence interval between 0.190 to 0.348 . Because the three confidence intervals do not intersect and the estimated confidence interval average on the TOPSIS method is smaller, it can be said that the TOPSIS method optimizes the agility response with a specification limit of $0-1.25 \mathrm{~mm}$.

The utilization of the Taguchi method currently carried out by manufacturing companies around the world is influenced by globalization and forced to become more competitive every day to maintain profitability and be able to produce products that meet specifications. The implementation of total quality is the principle that is applied as one of the strongest indicators of a company's competitiveness. Quality or quality is the level of good or bad level or degree of something. This term is widely used in relation to techniques and concepts to improve the quality of a product or service. It is impossible to produce quality products and services without going through humans and quality products. Good quality is if the combination between process parameters is appropriate. The optimal combination is obtained by optimization. Optimization is defined as the search for variable values that are considered optimal, effective, and efficient to achieve the desired results. The Taguchi method is one of the experimental design methods that is often used, because of effective and efficient considerations. The Taguchi method is an efficient approach that uses experimental design to produce a combination of factors or levels that can be controlled by improving the quality of products and processes while reducing costs and resources to a minimum. The Taguchi method seeks to achieve this goal by making products or processes "insensitive" to various factors such as materials, manufacturing equipment, human labor, and operational conditions. The Taguchi method makes the product or process robust to noise factors, so this method is also called robust design (Taguchi 1987), Balavendram (1995). One of the uses of this method is in stationery envelope manufacturing industries, as the authors describe above.

\section{Conclusion and Suggestions}

Based on the analysis that has been done, it can be concluded that: a). In the second Taguchi method the response produces the optimal combination between different levels, thus indicating that the Taguchi method is not consistent in generating the optimal combination of factors when multirespon, thus requiring additional methods as Taguchi optimization to solve multirespon problems with the VIKOR and TOPSIS methods.

The combination of process level factors is obtained simultaneously to optimize brightness and soreness namely A3B2C1D1, maximum engine rotational speed of $150 \mathrm{rpm}$, medium mixer rotational speed $225 \mathrm{rpm}$, minimum viscosity of $50 \mathrm{cP}$ and vacuum pump suction pressure valve is opened in half with suction pressure of only $35 \mathrm{psi}$ for the VIKOR method. While the optimum combination of process level with TOPSIS A1B1C3D3 method, minimum engine rotational speed of $85 \mathrm{rpm}$, mixer rotational speed of $150 \mathrm{rpm}$, maximum viscosity of $100 \mathrm{cP}$ and vacuum pump suction pressure valve is opened in half with suction pressure reaching 75 psi.

The estimated value of the optimization results at the optimum conditions obtained by the VIKOR and TOPSIS methods yield the best predictive values respectively for brightness using the VIKOR method of 79.772 Labs, and the TOPSIS method is 81.031 Labs away from the target specified specifications 79-81 Lab. While for Kesikuan the best predictive value was successively using the TOPSIS method which was $0.269 \mathrm{~mm}$ which produced the smallest characteristic, then followed by the VIKOR method of $1.14 \mathrm{~mm}$ with a specificity limit of $0-1.25 \mathrm{~mm}$.

Suggestions that can be given in this study is that an experimental confirmation is needed, namely by doing a number of repeat experiments based on the optimum settings obtained to determine the most optimum combination and try another method to produce optimum optimum setting with different weight values.

\section{References}

Balavendram N. 1995. Quality by Design. Great Britain: Prentice Hall International. 
Datta, Saurav., Siba Sankar Mahapatra, Sabhyasachi Banerjee, Asish Bandyopadhyay. 2010. Comparative Study on Application of Utility Concept and VIKOR Method for Vendor Selection. AIMS International Conference on Value-based Management. pp 614-622.

Derringer, G dan Suich, R. 1980. Simultaneous Optimization of Several Response Variables. Journal of the Quality Technology, Vol. 12, pp 214-219.

Gaitode,V. N., Karnik S. R., Achyutha. B. T., dan Siddeswarappa. B. 2006. Multi-Response Optimization In Drillig Using Taguchi's Quality Loss Function. Indian Journal of Enggineering and Materials Science, Vol. 13, No. 6, pp 484-488.

Garg, R. 2010. Effect of Process Parameters on Performance Measures of Wire Electrical Discharge Machining. Ph. D. Thesis, Mechanical Engineering Departement, National Institute of Technology, Kurukshetra, Haryana, India.

Kahraman, C. 2008. Multi-Criteria Decision Making Methods and Fuzzy Sets. Fuzzy Multi-Criteria Decision Making, Theory and applications with recent Development. Springer.

Khezrian, M,. Kadir,. Wan M. N. Wan,. Suhaimi Ibrahim, and Alaeddin Kalantari. 2011. Service Selection based on VIKOR method. International Journal of Research and Reviews in Computer Science (IJRRCS) Vol. 2, No. 5, ISSN: 2079-2557.

Khuri, A. I. dan Conlon, M. 1981. Simultaneous Optimization of Multiple Responses Represented by Polynomial Regression Function. Technometrics, Vol. 23, pp 363-375.

Liao, Hung-Chang. 2004. A data envelopment analysis method for optimizing multi-response problem with censored data in the Taguchi method. Computers \& Industrial Engineering. 46 pp. 817-835.

Lin, J.L., Wang, K.S., Yan, B.H,. Tarng, Y.S. 2000. Optimization of The Electrical Discharge Machining Process Based on The Taguchi Method with Fuzzy Logics. Journal of Materials Processing Technology. 102 pp. 48-55.

Lu, H.S, J.Y. Chen dan Ch. T. Chung. 2008. The Optimal Cutting Parameter Design Of Rough Cutting Process In Side Milling. Journal of Achievment in Materials and Manufacturing Engineering, volume 29 issue 2.

Mohammady, P. and A. Amid. 2010. "Integrated Fuzzy VIKOR and Fuzzy AHP Model for Supplier Selection in an Agile and Modular Virtual Enterprise Application of FMCDM on Service Companies". The Journal of Mathematics and Computer Science. 4(1): pp. 413-434.

Nike, D. Y. 2008. Penerapan Metode Taguchi \& Pendekatan Metode Data Envolopment Analysis (DEA) Based Ranking Dalam Mengoptimasian Parameter Kualitas Kertas Pada Proses Paper Machine II (studi kasus : di PT. Adiprima Saraprinta Gresik). Tugas Akhir. Jurusan Statisstika Institut Teknologi Sepuluh November Surabaya.

Opricovic, Serafim dan Tzeng, Gwo-Hshiung. 2007. Extended VIKOR Method in Comparison with Outranking Method. European Journal of Operational Research. pp 514-529.

Rahmasari, Fauzhia. 2017. Optimasi Multirespon Metode Taguchi Menggunakan PCA-TOPSIS Dan Metode VIKOR. Sekolah Pascasarjana. Institut Pertanıan Bogor

Refaie, A. Al dan Li, M.H. 2008. Proceedings of the World Congress on Engineering. Vol II WCE 2008, July 2 4. London, U.K.

Sathees M dan Dhas JER. 2013. Multi objective optimization of flux cored arc weld parameters using fuzzy based desirability function. Mechanical Engineering, Vol. 37, No. M2, pp 175-187. Shiraz University. 
Setyabudhi, A.L. 2012. Optimasi Brightness dan Kesikuan pada Proses Pembuatan Amplop dengan Pendekatan Taguchi Multirespon. Tesis Program Studi Magister Manajemen Teknologi Institut Teknologi Sepuluh Nopember Surabaya.

Suniantara, I Ketut Putu. 2013. Pendekatan Metode Vikor Untuk Mengatasi Optimasi Multirespon Pada Metode Taguchi, (Studi Kasus Pada Proses Pembuatan Amplop). Tesis. Jurusan Statisstika Institut Teknologi Sepuluh November Surabaya.

Taguchi G. 1987. System of Experimental Design, Vol. 1 dan 2. New York: Unipub Kraus International Publications.

Tong, Lee-Ing., Su, Chao-Ton. 1997. Optimizing Multi-Response Problems in The Taguchi Method by Fuzzy Multiple Attribute Decision Making. Journal Quality and Reliability Engineering International.

Tong, Lee-Ing., Chen, Chi-Chan., Wang, Chung-Ho. 2007. Optimzation of Multi-Multiresponse Processes Using the VIKOR Method. Int J Adv Manuf Technol, edisi 31, pp 1049-1057 